\title{
Analysis of Monthly and Seasonal Groundwater Fluctuations in Zimbabwe: A Remote Sensing Perspective
}

\section{David Chikodzi*}

Great Zimbabwe University, Masvingo, Zimbabwe

\begin{abstract}
The main aim of the research was to produce seasonal and yearly groundwater fluctuations in catchments around Zimbabwe from a remote sensing perspective so as to identify patterns of groundwater depletion and recharge. This information is vital so as to ensure that groundwater development in Zimbabwe proceeds in parallel with the effective evaluation and management of the resource. In Zimbabwe, measurement, monitoring and analysis of groundwater levels is limited and completely absent in some areas because of the costs involved. The research used monthly GRACE satellite data from 2004-2010 with a spatial resolution of $20 * 20$ kilometres. The data was imported into a Geographical Information System, interpolated using the moving average method and then statistically analysed to show average monthly fluctuations and average yearly fluctuation patterns in catchments around Zimbabwe. The results showed that the average groundwater levels in Zimbabwe are about $0.92 \mathrm{~cm}$ above the long term mean level and have a declining trend line. The results show that the average monthly and seasonal groundwater levels in Zimbabwe are declining with more seasons and months recording below average levels. The study also produced a new method of rapid assessment of groundwater resources which is also considerably cheap.
\end{abstract}

Keywords: Groundwater; Monthly groundwater fluctuations; Seasonal groundwater fluctuations; GIS; Remote sensing; Grace satellite

\section{Introduction}

Groundwater is a highly valuable resource to the nation as majority of the agricultural, domestic, and industrial activities depends on it. Groundwater is acquired by constructing and operating extraction wells and boreholes. The measurement and analysis of groundwater levels is needed for maintaining groundwater availability. However, across the Southern African region, groundwater monitoring is limited or absent. Groundwater monitoring systems along with good institutional support are vital for gathering, collating and analysing the information that is needed to ensure that groundwater development proceeds in parallel with the effective evaluation and management of the resource [1].

In Zimbabwe groundwater resources provide the highest potential of coping with, and mitigating the impacts of, climate change and increasing food production because it responds much more slowly to changes in meteorological conditions than surface water. As a result groundwater provides a natural buffer against the effects of climate change and variability, including drought [2-4]. Bates et al. [5] noted that the major uncertainty lies in how changes in climate may affect groundwater and what resources are currently available to help support adaptation strategies. Many countries in Africa with severe groundwater depletion problems have limited information on the spatial and temporal variability in groundwater storage [6], as monitoring networks are generally limited and it is difficult to regionalise point-based measurements $[1,7,8]$.

Despite the importance and potential of groundwater to Zimbabwe, there have been limited direct measurements of groundwater fluctuations over time to guide informed decision making and planning on the sustainable exploitation of the resource. This is because generally groundwater monitoring is very expensive and needs well trained manpower $[1,9,10]$. In this regard there is need to develop cheaper methods that are equally accurate and also give a regional perspective of groundwater fluctuations in Zimbabwe. In this study, we explore the utility of remotely sensed data in producing seasonal and yearly groundwater fluctuations in catchments around Zimbabwe with the aim of identifying patterns of groundwater depletion and recharge within the catchments.

\section{Materials and Methods}

\section{Area of study}

The study was conducted in the whole of Zimbabwe (Figure 1). Water resources management in Zimbabwe is delegated to autonomous bodies called catchment councils. Zimbabwe is divided into seven major catchments which are Manyame, Mazowe,c Gwayi, Sanyati, Save, Mzingwane and Runde. Analysis of the data on monthly and annual groundwater fluctuations will therefore be done mainly using these catchments.

\section{Remotely sensed data}

Remote sensing, and in this case the Gravity Recovery and Climate Experiment (GRACE) satellites, have the potential to provide relatively cheaper ways of obtaining information on groundwater fluctuations of an area at a regional level [11]. GRACE satellite data has an important role to play in Zimbabwe because fieldwork-based monitoring techniques of groundwater are difficult and expensive to set up and maintain. The GRACE satellite data can also be used together with point data when available to detect regional-scale changes in groundwater resources.

*Corresponding author: David Chikodzi, Great Zimbabwe University, Masvingo, Zimbabwe, E-mail: dchikodzi@hotmail.com

Received December 20, 2012; Accepted January 29, 2013; Published January 31, 2013

Citation: Chikodzi D (2012) Analysis of Monthly and Seasonal Groundwater Fluctuations in Zimbabwe: A Remote Sensing Perspective. Hydrol Current Res S1:003. doi:10.4172/2157-7587.S1-003

Copyright: (c) 2012 Chikodzi D. This is an open-access article distributed under the terms of the Creative Commons Attribution License, which permits unrestricted use, distribution, and reproduction in any medium, provided the original author and source are credited. 


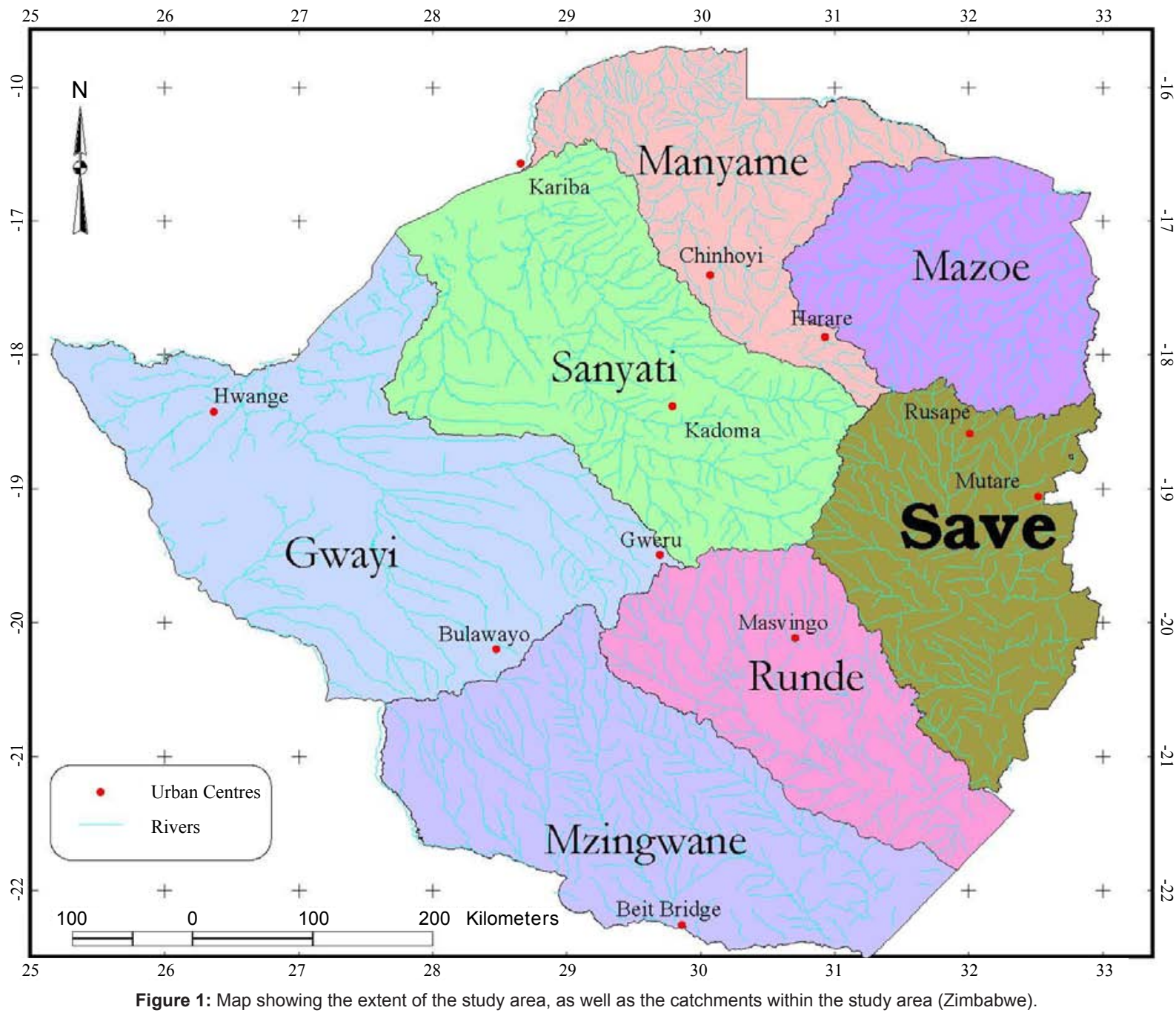

The GRACE satellites do not measure variations in groundwater storage directly, but instead measure the Earth's gravitational field. Unlike most missions, the satellites themselves act as the measurement devices. The GRACE system consists of two chasing satellites (also called Tom and Jerry). When the satellites pass over a mass of water, an increase in the pull of gravity is recorded, leading to an acceleration of that satellite. In the case of GRACE, when the leading satellite is passing over the mass of water, it will accelerate first and then decelerates when it is past the mass of water. The second satellite also accelerates when it passes over the same mass of water and catches up with the leading satellite. Thus, differences in the groundwater levels induce gravity disparities which lead to distance variations between the two satellites $[11,12]$.

The GPS location of each satellite is precisely recorded, and a microwave ranging system measures changes in distance between the two satellites to within $10 \mathrm{~mm}[12,13]$. The GRACE project then uses measured variations in the range rate between the two satellites and other tracking data to estimate gravitational coefficients, along with other dynamical orbit parameters, in a least squares estimation to maximize the fit between a modelled orbit (based on gravitational potential) and the measurements [14].

Estimations of the gravity field coefficients are made approximately every month to spherical harmonic degree and order 60. Spherical harmonics are two dimensional basis functions represented by Legendere polynomials and cosine and sine functions of order time the longitude [11]. The conversion of the time-variable gravity field coefficients to maps of surface mass density (groundwater fluctuations) are based on the assumption that for periods less than several hundred years, the primary cause of temporal changes in the Earth's gravity field is the movement of masses of water within the Earth's relatively thin fluid envelope [13].

\section{Data analysis}

The geo-referenced GRACE satellite data comes in monthly text data tables covering the whole world and so the data covering Zimbabwe was first subsetted. The subset tables were then individually imported into the Intergrated Land and Water Information Systems (ILWIS) GIS. The imported tables were then converted to point maps showing the point fluctuations of groundwater levels. In order to obtain a map showing the spatial variations of groundwater levels for individual months, we interpolated the point maps using the moving average function. The moving average function assigns, to an output pixel, a weighted average of point values within a defined neighbourhood. The moving average function uses the inverse distance algorithm in order 
to ensure that points close to an output pixel obtain larger weights than points which are further away from it.

The map list function was used to group monthly images from the same year (January-December) into a composite map showing the distribution of groundwater within a season. This meant that seven composite maps where produced from 2004-2010. The resulting map lists where then averaged out using the average function in the Map List Statistics Operation in order to obtain the annual mean levels of groundwater.

The map list function was also used to group images from the same month into a composite map covering the period from 2004-2010. All in all, a total of 12 map lists for each month from January to December were created. Each of the obtained map lists were then averaged out using the average function in the Map List Statistics Operation. The resulting raster maps were long-term average groundwater levels for each of the 12 months. The average monthly means of groundwater fluctuations were then combined into a map list which was then averaged out to give out final long-term average behaviour of groundwater.

A number of studies have validated GRACE derived groundwater fluctuations with field data derived from monitoring wells and boreholes. These ground verification exercises have been done in a variety of environments around the world, namely in humid tropics (Brazil), in monsoon climates (India and Bangladesh) and in semi arid regions with climate similar to Zimbabwe (Australia, Niger and the High Plains aquifer, Central United States). All these studies show a good fit between GRACE-derived groundwater fluctuations and in situ borehole records, with discrepancies between the two data sets varying from 2.1-3.5 cm [15-17]. In this regard, we conclude that GRACE Satellite data can safely be used over Zimbabwe.

\section{Results}

Figure 2 shows the average monthly cycle for groundwater resources in Zimbabwe from 2004-2010 \& it also shows that from January through to June all the areas in Zimbabwe will be having possitive groundwater levels compared to their longterm averages. In particular, catchments in the northern parts of the country namely Mazowe, Manyame and Sanyati have the largest magnitude of recharge of groundwater. The rate of recharge of groundwater of declines as one moves to the southern catchments.

By July, all catchments in the country will be having negative values of groundwater compared to their longterm mean levels. The catchments in the north have high rates of groundwater release than those to the south of the country. By December recharge of groundwater will have began and only the Zambezi Valley will be having negative water table levels, the rest of the catchmets are quick to respond to groundwater recharge.

Figure 3 Shows the annual average changes in the groundwater for all catchments in Zimbabwe. Figure 4 shows that only 2004, 2008 and 2009 had mainly positive groundwater levels for all the catchments compared to their longterm mean. The rest o the years record mostly negetive level, this shows that, on average, there are now more years of groundwater shortage than there are surpluses, showing an overal decline in groundwater levels in all of Zimbabwe's catchments. From 2008-2010 there seems to be a consistant pattern of groundwater shortages for the Mzingwane, Runde and Parts of the Save Catchments.

Figure 4 shows the average fluctuations of ground water levels in Zimbabwe from 2004 to 2010. The figure reveals that the levels of groundwater in Zimbabwe (on average, $0.92 \mathrm{~cm}$ ) are shown to decline as shown by the negative trend line in the time series correlation. Particularly, groundwater in Zimbabwe's catchment area had a sudden drop in 2005 from an average of nearly $30 \mathrm{~cm}$ to fluctuations between 15 to $10 \mathrm{~cm}$

\section{Discussion}

Geological formations and rainfall totals are the main factors explaining the observed groundwater trends in Zimbabwe. The groundwater level declines are usually greatest in the upland recharge areas where groundwater levels are typically at a higher elevation. Groundwater-levels at lower elevations near valley bottoms, which are groundwater discharge areas, generally show much less change in groundwater decline than the higher ground $[1,18]$.

Zimbabwe's catchments are covered $60 \%$ by crystalline basement rocks $[19,20]$. Groundwater occurrence in the crystalline basement aquifers is characterised by the presence of a shallow water table and recharge is mainly from rainfall [21]. The occurrence of groundwater in hard rock is confined to the shallow weathered zones $[1,18]$. The groundwater gets depleted due to outflow of groundwater which ultimately leaks out to the streams and drainages as a base flow. The groundwater system is dynamic and shown (Figure 2), that whether extracted or not, it does not remain static and gets depleted hence the negative water table at least at one point in time during the year for every area in Zimbabwe. The nothern catchments in Zimbabwe have higher hydraulic transmisivity rates than the rest of the catchments because of the mostly steep terraine in which they occur encouraging rapid water lose from the catchments $[18,20]$.
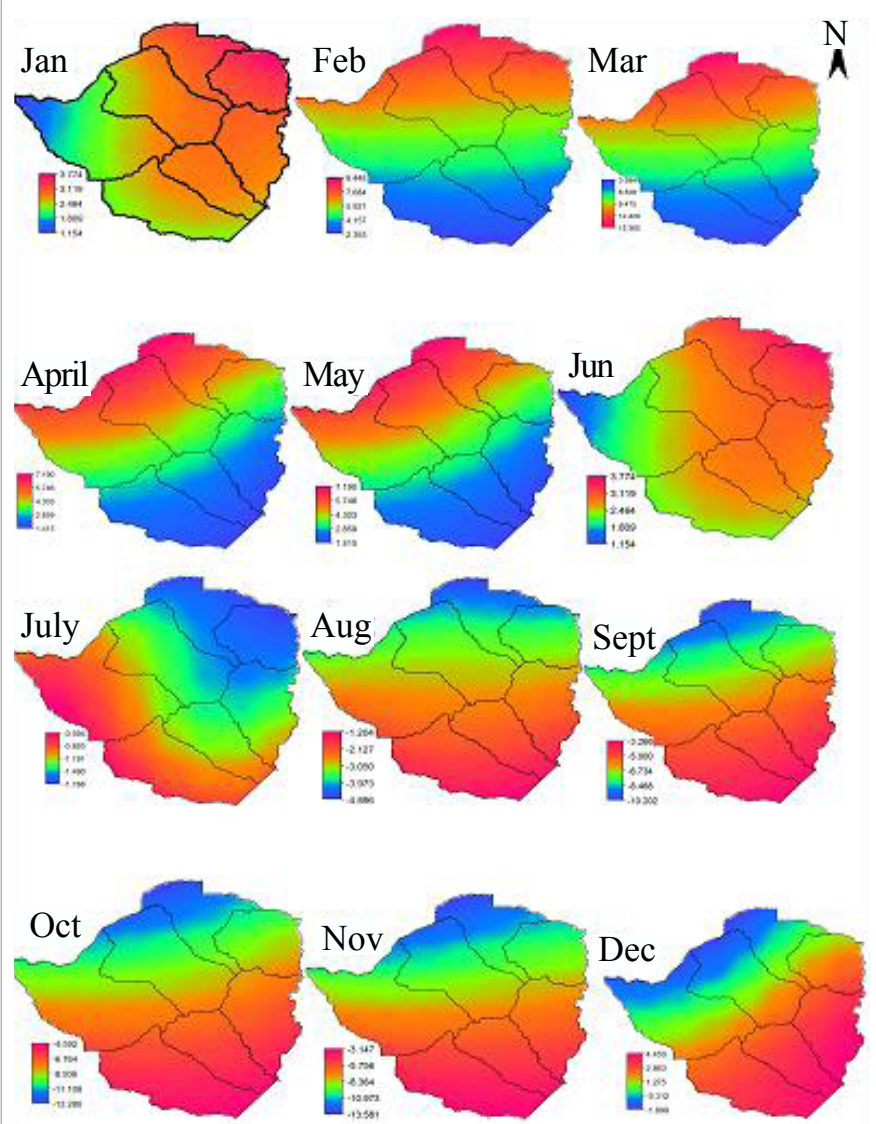

Figure 2: Average monthly groundwater fluctuations in $\mathrm{cm}$ for the period between 2004 to 2010 . 


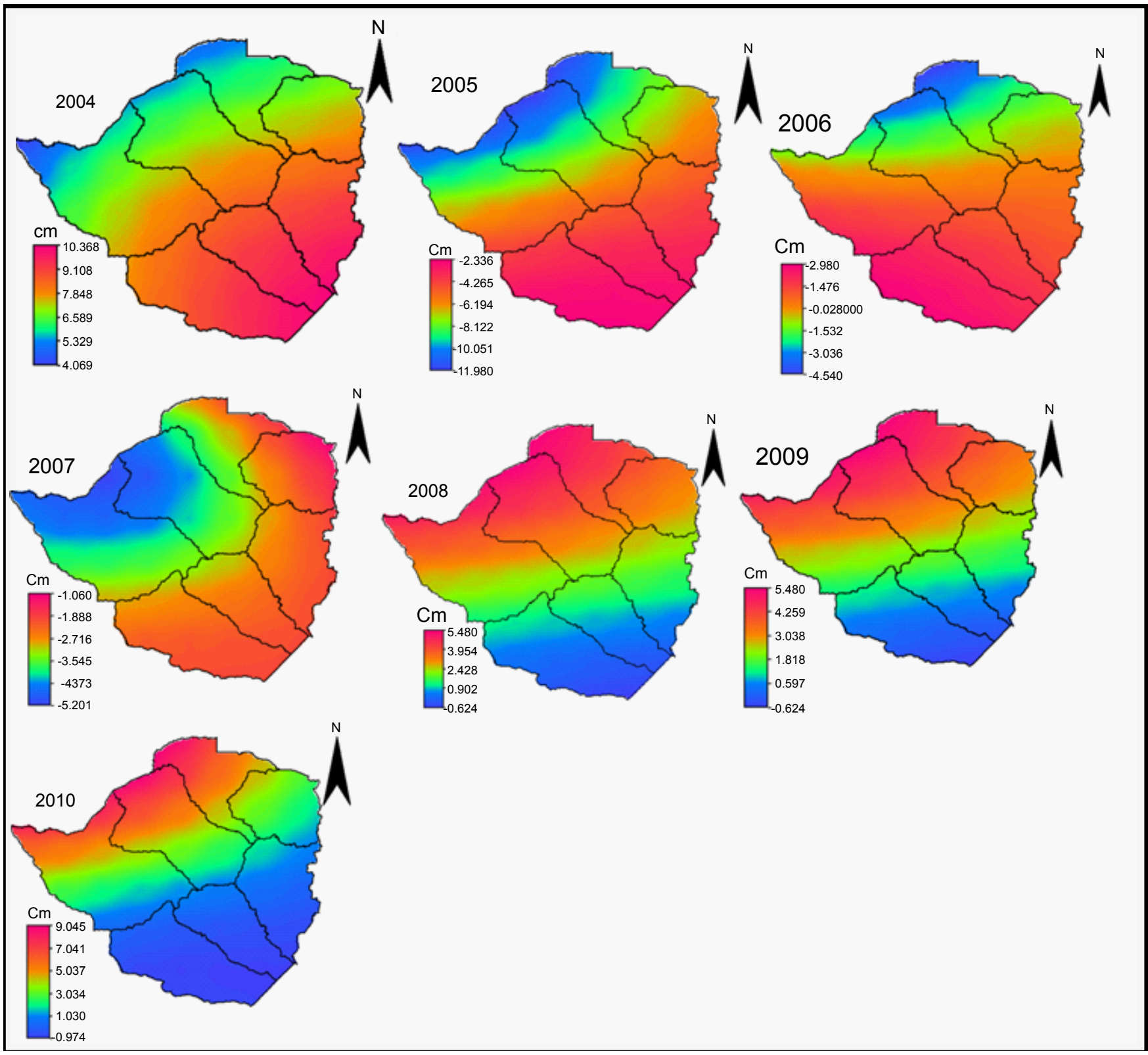

Figure 3: Average annual groundwater fluctuations about the longterm average mean for the period 2004-2010.

Based on our findings only in 2004, the whole of Zimbabwe exhibited a big magnitude of the positive correlation. The following years showed declining trends with only two seasons that gave positive recharge for the entire country which were way below the 2004 peaks. This can be explained only by the decline in rainfall patterns throughout the country during the time in question. This is consistant to what [22] have reported concerning the long term climatic scenarions of Zimbabwe. They report that precipitation activity in Zimbabwe is showing a declining trend which has also seen an increase in the magnitude and frequency of dryspell activities. The frequency of reduced precipitation has increased with more seasons of below normal rainfall increasing since 2002 .

The relatively fast response of Zimbabwe's groundwater to recharge by precipitation can be explained by the fact that most aquifers that occurr in the country are unconfined, shallow and a product of crystalline basement rock [21,23]. When recharge occurs in an unconfined and shallow aquifer, the water table rises to a higher elevation much quicker than for example, the water level in a can will rise as water is added to it. $2 \mathrm{~mm}$ of precipitation for example moving underground to the water table will cause the groundwater level to rise considerably more than an $2 \mathrm{~mm}$. This is because unlike a can, most of the volume of an aquifer is occupied by rock, sand or other solid geologic material. The water can only occupy the void or pore spaces.

\section{Conclusion}

The research can therefore be concluded that groundwater levels in most parts of Zimbabwe's catchments are in a state of decline as proved by the negative trend line equation on Figure 4 . Groundwater in Zimbabwe is quick to respond to the input factor of precipitation as shown by the quick transition from negative to positive groundwater 
Citation: Chikodzi D (2012) Analysis of Monthly and Seasonal Groundwater Fluctuations in Zimbabwe: A Remote Sensing Perspective. Hydrol Current Res S1:003. doi:10.4172/2157-7587.S1-003

Page 5 of 5

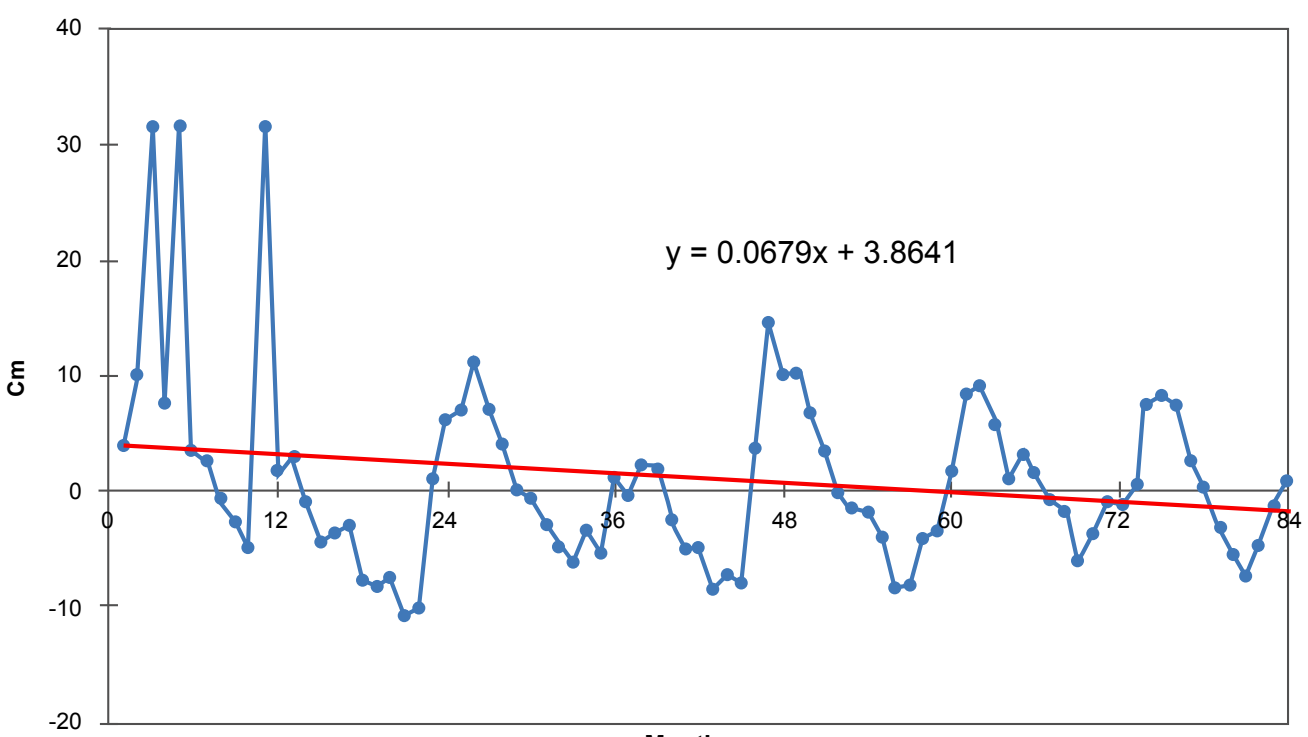

Months

Figure 4: Average monthly groundwater fluctuations for 84 months from 2004-2010.

levels during the onset of the rainfall season in mid November. However most of the catchments are also quick to release groundwater as shown by the decline in groundwater levels soon after the end of the rainfall season. The loss of groundwater is mainly controlled by geology and the geomorphology of catchments. The higher and steep sloped part of catchments loses water quicker for example the Zambezi escarpment to the north of the country than the low laying and flat terrain for example the south-east low veld of Zimbabwe. Over the years from 2004-2010, groundwater has shown a declining trend which is consistent with decline in rainfall amounts for the same time.

\section{References}

1. Anayah F, Kaluarachchi JJ (2009) Groundwater resources of northern Ghana: Initial assessment of data availability. Utah State University, College of Engineering Report, Logan, USA.

2. Calow RC, Robins NS, MacDonald AM, Macdonald DMJ, Gibbs BR, et al. (1997) Groundwater management in drought prone areas of Africa. Int J Water Res Dev 13: 241-262.

3. Giordano M (2009) Global groundwater? Issues and solutions. Annu Rev Environ Resour 34: 153-178.

4. MacDonald AM and Calow RC (2009) Developing groundwater for secure rural water supplies in Africa. Desalination 248: 546-556.

5. Bates B, Kundzewicz ZW, Wu S, Palutikof JP (2008) Climate change and water. Technical Paper of the Intergovernmental Panel on Climate Change (Geneva: IPCC Secretariat).

6. Shah T, Molden D, Sakthivadivel R, Seckler D (2000) The global groundwater situation: Overview and opportunities and challenges. Int Water Manage Inst, Colombo, Sri Lanka.

7. Foster SSD, Chilton PJ (2003) Groundwater: the processes and global significance of aquifer degradation. Phil Trans R Soc B 258: 1957-1972.

8. Jyrkama MI, Sykes JF (2007) The impact of climate change on spatially varying groundwater recharge in the grand river watershed (Ontario). Journal of Hydrology 338: 237-250.

9. Bonifacio R, Grimes DIF (1998) Drought and Flood Warning in Southern Africa. IDNDR Flagship Programme, Thomas Telford, London.

10. Nathan RJ, McMahon TA (1992) Estimating low flow characteristics in ungauged catchments. Water Resources Management 6: 85-100.

11. Strassberg G, Scanlon BR, Rodell M (2007) Comparison of seasonal terrestrial water storage variations from GRACE with groundwater-level measurements from the High Plains Aquifer (USA). Geophysical Research Letters: 34.

12. Tapley BD, Bettadpur S, Ries JC, Thompson PF, Watkins MM (2004) GRACE measurements of mass variability in the Earth system. Science 305: 503- 505

13. Wahr J, Swenson S, Zlotnicki V, Velicogna I (2004) Time-variable gravity from GRACE: First results. Geophys Res Lett: 31.

14. Bettadpur S (2007) Level-2 Gravity Field Product User Handbook (Rev. 2.3 February 20, 2007) Center for Space Research, University of Texas at Austin.

15. Syed TH, JS Famiglietti, Chen J, Rodell M, Seneviratne SI, et al. (2005) Total basin discharge for the Amazon and Mississippi River basins from GRACE and a land-atmosphere water balance. Geophys Res Lett: 32 .

16. Rodell, M, Chen J, Kato H, Famiglietti JS, Nigro J, et al. (2007) Estimating groundwater storage changes in the Mississippi River basin (USA) using GRACE. Hydrogeol J 15: 159-166.

17. Swenson S, Famiglietti J, Basara J, Wahr J (2008) Estimating profile soil moisture and groundwater variations using GRACE and Oklahoma Mesonet soil moisture data. Water Resour Res: 44.

18. Karanth KR (1987) Ground Water Assessment: Development and Management Tata McGraw Hill, New Delhi.

19. Acres BD, Rains AB, King RB, Lawton RM, Mitchell AJB, et al. (1985) African dambos: their distribution, characteristics and use. Zeitschrift fu" $r$ Geomorphologie Supplementbande 52: 62-83.

20. Whitlow JR (1988) Degradation of Wetlands. Influence of Human Factors on Erosion, Land Degradation in Zimbabwe, Report prepared by the Department of Natural Resources.

21. Bullock A (1992) Dambo hydrology in southern Africa-review and reassessment. Journal of Hydrology 134: 373-396.

22. Simba FM, Murwendo T, Chikodzi, Mapurisa B, Munthali A et al. (2012) Environmental changes and farm productivity: a case study of Masvingo Province in Zimbabwe. Sacha Journal of Environmental Studies 2: 114-129.

23. McFarlane MJ (1989) Dambos- Their Charateristics and Geomorphologica evolution in parts of Malawi and Zimbabwe with particular reference to the role in the hydrogeological regime of areas of African surface. In groundwater Exploration and development in Crystalline Basement Aquifers 2. Commonwealth Science Publication.

This article was originally published in a special issue, Water Resources Research handled by Editor(s). Dr. Maria Papadaki, University of Leeds, United Kingdom 